\title{
Quantitative thermal perception thresholds relative to exposure to vibration
}

\author{
T Nilsson, R Lundström
}

\begin{abstract}
Objectives-To assess the risk of disturbed thermal perception relative to exposure to vibration, to investigate a possible exposure-response relation and to analyse a possible relation between thermal perception and sensory symptoms.

Methods-The study was based on a cross section of 123 male workers exposed to vibration and 62 male workers who were not exposed. Thermal perception of cold, warmth, and heat pain was bilaterally determined from the thenar eminence by the method of limits. Perception of cold and warmth were also tested in the second digit. Personal energy equivalent exposure to vibration was measured for all subjects. Vibration was measured in accordance with International Standards Organisation (ISO) 5349 and assessed separately for the left and right hand. Results-Combining exposure times and intensities gave the left hand an 0.80 exposure to vibration compared with the right. The risk of having contracted reduced thermal perception was increased at all test sites. The risk was higher for the thenar measurements than the finger measurements. A yearly extra contribution of $4000 \mathrm{mh} / \mathrm{s}^{2}$ in cumulative exposure increases the risk of contracting a wider neutral zone by $18 \%$ (95\% confidence interval $(95 \% \mathrm{CI}) 1.06$ to 1.32$)$ for the right and $18 \%(1.05$ to 1.32$)$ for the left hand side. Subjects with symptoms of nocturnal paraesthesia had a rate ratio $(95 \% \mathrm{CI})$ of 2.80 (1.17 to 6.67 ) for the right hand and 2.72 (1.12 to 6.63) for the left hand for increased neutral zones at the thenar eminence.

Conclusions-The results indicate thermal sensory impairment related to cumulative exposure to vibration. The effect appeared at vibration levels below the current guiding standard. Quantitative sensory testing of thermal perception offers the chance to assess this specific hazard to the peripheral sensorineural system associated with hand intensive work entailing vibration.

(Occup Environ Med 2001;58:472-478)
\end{abstract}

Keywords: quantitative thermal perception; heat pain; vibration; temperature threshold

Critical reviews of the epidemiology literature have identified several specific physical exposures associated with certain work related neuromusculoskeletal disorders. ${ }^{1}$ For example, work in occupations entailing awkward postures, repetitive tasks, high musculoskeletal load, and physical factors such as cold, vibration, and mechanical stress, is related to disorders with neuropathic symptoms. ${ }^{2}$ The symptoms may reflect either "negative" (loss of sensation) or "positive" (paraesthesia) manifestations of nerve fibre dysfunction. ${ }^{3}$ Important discrepancies in the evaluation of sensory disturbances have been noted as there are symptoms unaccompanied by signs. There are also situations where sensory impairment is shown by testing in the absence of subjective complaints.

In neuropathy associated with vibration the conceivable target structures could be the end organs, the large myelinated $(A \alpha, A \beta)$, the thinly myelinated $(\mathrm{A} \delta)$, and the small calibre non-myelinated (C) fibres. Large diameter fibres mediate impulses from tactile perception (touch, pressure, vibration), whereas the small diameter fibres conduct thermal stimuli and pain. Results from animal experiments suggest that the large and thin fibre afferent nerves might be unequally affected by the possible pathogenic influences from local exposure to vibration. ${ }^{4}$ Experiments on the temporary shift in threshold of thermal perception induced by vibration indicate that the effect from vibration has a greater impact on the perception of cold than on warmth. ${ }^{5}$ Hypoaesthesia of the sensation of warmth is claimed to be more prevalent at the early stages of vibration disease whereas hypoaesthesia to cold occurs at more advanced stages of hand-arm vibration disease. ${ }^{6}$

The present study focuses on the effect of vibration on the function of the small calibre naked nerve endings with thin unmyelinated nerve fibres transmitting the sense of cold, warmth, and heat pain.

The aims of the present investigation were threefold: to assess the risk of disturbed thermal perception developing among platers (steel manufacting workers exposed to vibration) and non-exposed office workers, to assess the possible exposure-response relation between exposure to vibration and disturbed thermal perception and to analyse the possible relation between thermal perception and sensory symptoms.

\section{Material and methods}

STUDY DESIGN

The investigation was based on a cross sectional study of 123 male workers exposed to vibration and 62 not exposed (table 1). The workers were from a dynamic cohort. The study was conducted at the 5 year follow up examination, at which there was a $93 \%$ participation rate. The study population included all 
Table 1 Descriptions of subjects (number, age, nicotine use, and number excluded) relative to cross sectional cumulative exposure to vibration (CVE) and to exposure classes

\begin{tabular}{|c|c|c|c|c|c|c|}
\hline & \multicolumn{3}{|l|}{ Cumulative exposure } & \multicolumn{3}{|c|}{ Cumulative lifetime exposure } \\
\hline & $\begin{array}{l}\text { Never exposed or } \\
\text { exposed before } 1987\end{array}$ & $\begin{array}{l}\text { Not exposed } \\
\text { during past } 5 \text { y }\end{array}$ & $\begin{array}{l}\text { Exposed } \\
\text { during past } 5 y\end{array}$ & $\begin{array}{l}N E, \\
C V E=0 \\
\mathrm{mh} / \mathrm{s}^{2}\end{array}$ & $\begin{array}{l}E C 1, \\
C V E \leqslant 24000 \\
\mathrm{mh} / \mathrm{s}^{2}\end{array}$ & $\begin{array}{l}E C 2, \\
C V E>24000 \\
\mathrm{mh} / \mathrm{s}^{2}\end{array}$ \\
\hline Number (n) & 83 & 50 & 52 & 62 & 70 & 53 \\
\hline Excluded (n) & 2 & 6 & 4 & 3 & 2 & 7 \\
\hline Age (mean (SD)) & $39.4(11.6)$ & $43.4(10.1)$ & $38.4(8.9)$ & $40.7(11.5)$ & $36.4(10.7)$ & $45.7(6.4)$ \\
\hline Nicotine use (n) & 45 & 23 & 29 & 25 & 44 & 28 \\
\hline
\end{tabular}

platers available for quantitative sensory testing and randomly selected office workers from a source population of 500. The work tasks of those professionally exposed to vibration consisted mainly of welding, plating, and grinding on iron and stainless steel. The work of the non-exposed group varied from construction at a desk to supervision and selling. Table 1 contains details of the characteristics of the study population.

Each subject was interviewed and examined by a physician, a procedure which was supplemented with chemical laboratory screening and lower limb nerve conduction measurements. These investigations were performed to check for the presence of other diseases, primarily polyneuropathy, which might interfere with the outcome. The examination results formed the basis for possible exclusion of some subjects. The criteria for rejection were former hand surgery or clinical signs of polyneuropathy together with abnormal sural nerve conduction. Twelve subjects were eventually excluded, mainly on the grounds of former hand surgery or electroneurographic test results of carpal tunnel syndrome $(n=8)$, polyneuropathy related to diabetes $(n=2)$, or unclassified $(\mathrm{n}=2)$.

The subjects also provided supplementary data in a questionnaire. The questions covered age, work, years at work, exposure, use of nicotine, and symptoms. Information about symptoms of nocturnal paraesthesia was also asked for. Answers were given on a four grade scale; no, insignificant, some, and rather much (word by word translation from Swedish). The study protocol was approved by the regional professional ethics committee.

\section{ASSESSMENT OF THRESHOLDS OF THERMAL}

PERCEPTION

Thermal perception was determined by a Somedic modification of the Marstock method ${ }^{7}$ with computer assisted automatic exposure and response recording (Thermotest; Somedic, Sales AB, Sweden). A thermostimulator-a Peltier contact thermode-was applied to the skin . When measuring perception of cold and warmth the probe $(25 \times 50 \mathrm{~mm})$ was gently applied to the volar surface of the two distal phalanges of the second digit (lengthways along the finger) and to the thenar eminence on each hand respectively. Heat pain perception was only measured from the right and left thenar eminences. The perception threshold of cold, warmth, and pain induced by contact heat was assessed by the method of limits. The rate of the temperature change was linear and about $1^{\circ} \mathrm{C} / \mathrm{s}$. Before the quantitative evaluation of thermal sensibility, the skin temperature at each body site was measured by contact thermometry. A neutral starting temperature was accomplished by use of the skin temperature that the subject perceived as indifferent. The subject was instructed to press a switch whenever he experienced the onset of a change in the sensation of temperature (cold, warmth, and heat pain). The operating temperature range was set at $10-52^{\circ} \mathrm{C}$. After a response the temperature of the thermostimulator changed direction and returned to the neutral baseline temperature. The measurement of warmth and cold was repeated 10 times. The threshold was taken as the mean of the measurements. The neutral zone was defined as the temperature difference between the warm and cold perception thresholds. When assessing the sensation of heat pain the thermode temperature returned to a predetermined subjective neutral level, from where five consecutive stimulation trials were made. The interstimulus interval for all threshold measurements was randomly distributed within 2 seconds.

ASSESSMENT OF EXPOSURE TO VIBRATION

Personal energy equivalent exposures to vibration were measured for all subjects with the vibration intensity measured (1987 and 1992) and classified on a job-task basis together with exposure times. The intensity of tool vibration was measured on all types of tools and at all relevant job stations. The vibration was measured in accordance with the International Standards Organisation (ISO) 5349. ${ }^{8}$ The daily duration of exposure to vibration was subjectively assessed and also objectively assessed by measurement of the time for which each type of hand held tool was used. The observer noted the kind of tool the operator was handling, whether the machine was working, and which hand was exposed, for each minute during an observation time of 150 minutes. Each subject's exposure to vibration was calculated on the individual exposure time assessed from observation, questionnaires, and diaries, combined with the mean measured intensity of vibration for the dominant direction of the tools used. Furthermore, all platers were interviewed to obtain information about their entire lifetime exposures, about the number of years in different work, types of exposure, and duration of exposure per day. On that basis, the cumulative lifetime equivalent frequency weighted exposure to vibration was estimated. A detailed description of measurement was given in a separate report. ${ }^{9}$ Hand transmitted vibration most often occurred 
from use of grinders held in one or two hands $(65 \%)$. They were used for grinding, polishing, and cutting. Hammers used for finishing welding seams accounted for $25 \%$ of the use of tools in the assembly of machinery. Other tools, such as die grinders, drills, and nut wrenches, together accounted for about $10 \%$ of the total use at the company.

Based on the results from work analyses in 1987 and 1992, diary results from 1992, and vibration measurements both when the cohort was first investigated and at the follow up, a separate estimate of the exposure to vibration of either hand could be formed for each job title. Combining exposure times and intensities gave the left hand a 0.80 exposure compared with the right hand.

Cumulative exposure to vibration (CVE) was classified into three different categories. Non-exposed $\left(\mathrm{NE} ; \mathrm{CVE}=0 \mathrm{mh} / \mathrm{s}^{2}\right)$, exposure category $1\left(\mathrm{EC} 1 ; 0<\mathrm{CVE}=24000 \mathrm{mh} / \mathrm{s}^{2}\right)$, and exposure category 2 (EC2; CVE $>24000$ $\left.\mathrm{mh} / \mathrm{s}^{2}\right)$. The upper limit of EC1 corresponds, according ISO $5349,{ }^{10}$ to a $10 \%$ prevalence of vascular disorders after 10 years of exposure to a 4 hour equivalent frequency weighted acceleration $\left(a_{\mathrm{h}, \mathrm{w}}\right)_{4 \mathrm{~h}}$ level of $3 \mathrm{~m} / \mathrm{s}^{2}$.

\section{STATISTICS}

The difference in thermal perception threshold between the right and left hand measurements was calculated with the paired samples $t$ test. The mean difference in thermal perception between different exposure categories was analysed with independent group $t$ statistics and the association between effect and the different exposure categories with one way analysis of variance (ANOVA). The risk of having contracted a disturbed thermal perception threshold was given as a rate ratio. The case definition of "disturbed" perception was chosen as the total mean threshold value, based on all subjects, for each test site $\pm 1 \mathrm{SD}$ (table 2).

The criterion for being classified as having contracted nocturnal paraesthesia was the

Table 2 Case criteria (mean (SD)) defining impaired thermal threshold

\begin{tabular}{|c|c|c|c|c|}
\hline \multirow[b]{3}{*}{ Modality } & \multicolumn{4}{|l|}{ Test site } \\
\hline & \multicolumn{2}{|l|}{ Digit 2} & \multicolumn{2}{|l|}{ Thenar } \\
\hline & $\begin{array}{l}\text { Right hand } \\
{ }^{\circ} \mathrm{C}\end{array}$ & $\begin{array}{l}\text { Left hand } \\
{ }^{\circ} \mathrm{C}\end{array}$ & $\begin{array}{l}\text { Right hand } \\
{ }^{\circ} \mathrm{C}\end{array}$ & $\begin{array}{l}\text { Left hand } \\
{ }^{\circ} \mathrm{C}\end{array}$ \\
\hline Warmth & $>37.5(3.2)$ & $>36.9(3.1)$ & $>32.5(1.4)$ & $>32.1(1.4)$ \\
\hline Cold & $<22.1(3.0)$ & $<22.2(3.1)$ & $<25.9(1.3)$ & $<26.5(1.0)$ \\
\hline Neutral zone & $>14.5(5.3)$ & $>14.0(5.6)$ & $>6.3(2.3)$ & $>5.3(1.9)$ \\
\hline Heat pain & - & - & $>48.8(2.7)$ & $>48.7(2.8)$ \\
\hline
\end{tabular}

Table 3 Mean (SD) thermal thresholds for warm, cold, and neutral zone and heat pain as measured for the left and right hand sides at the thenar eminence and digit 2, and mean (95\% CI) difference between the left and right hand

\begin{tabular}{|c|c|c|c|c|c|}
\hline Test site & Modality & $\begin{array}{l}\text { Right hand } \\
{ }^{\circ} \mathrm{C}\end{array}$ & $\begin{array}{l}\text { Left hand } \\
{ }^{\circ} \mathrm{C}\end{array}$ & $\begin{array}{l}\text { Right-left difference } \\
{ }^{\circ} \mathrm{C}\end{array}$ & $95 \% C I$ \\
\hline \multirow[t]{4}{*}{ Digit 2} & Warmth & $34.34(3.2)$ & $33.80(3.1)$ & 0.54 & 0.13 to 0.95 \\
\hline & Cold & $25.09(3.0)$ & 25.28 (3.1) & -0.20 & -0.57 to 0.18 \\
\hline & Neutral zone & $9.25(5.3)$ & $8.51(5.6)$ & 0.73 & 0.09 to 1.38 \\
\hline & Heat pain & - & - & - & - \\
\hline \multirow[t]{4}{*}{ Thenar } & Warmth & $31.16(1.4)$ & $30.74(1.4)$ & 0.42 & 0.25 to 0.58 \\
\hline & Cold & $27.16(1.3)$ & $27.38(1.0)$ & -0.22 & -0.36 to -0.07 \\
\hline & Neutral zone & $4.00(2.3)$ & $3.36(1.9)$ & 0.64 & 0.37 to 0.90 \\
\hline & Heat pain & $46.12(2.7)$ & $46.00(2.6)$ & 0.12 & -0.14 to 0.38 \\
\hline
\end{tabular}

answer alternatives "some" and "rather much" symptoms on the four grade questionnaire scale.

The risk for contracting disturbed thermal perception for warmth, cold, and pain was estimated as crude rate ratios (Epi Info 6), as age was not regarded as a significant confounder. Confidence intervals were based on the Taylor series. The association between exposure to vibration and the neutral zone was tested with multiple logistic regression models (SPSS 7.5). The full model included the exposure factor accumulated vibration, and the possible confounders age, ${ }^{11}$ height, nicotine, and skin temperature. ${ }^{12}$ Modification of the effect of exposure to vibration by age was tested by the inclusion of an interaction term, but gave no significant effect and was rejected. Nicotine use was treated as a dichotomous variable whereas the others were treated as interval scales. The final model included the variables exposure to vibration, age, and starting temperature. Each unit change of cumulative exposure to vibration represents $4000 \mathrm{mh} / \mathrm{s}^{2}$, corresponding to an equivalent exposure of 1 year (200 days) of full time work ( 8 hours/day) at the European Community's currently recommended nonhazardous $\left(2.5 \mathrm{~m} / \mathrm{s}^{2}\right)$ exposure level. ${ }^{13}$ The quantitative relation between accumulated exposure to vibration and neutral zone gap was estimated by linear regression.

\section{Results}

The total mean perception thresholds at the thenar region, calculated over all groups and both hands, were $27.2^{\circ} \mathrm{C}$ for the sensation of cold, $31.0^{\circ} \mathrm{C}$ for warmth, and $46.0^{\circ} \mathrm{C}$ for contact heat pain. The corresponding values for the second digit were $25.1^{\circ} \mathrm{C}$ for cold and $34.2^{\circ} \mathrm{C}$ for warmth.

\section{OUTCOME RELATIVE TO HAND SIDE AND TEST}

SITE

The sensibility of the right hand side was slightly impaired compared with the left. The mean neutral zone was increased by $0.64^{\circ} \mathrm{C}$ (95\% confidence interval $(95 \% \mathrm{CI}) 0.37^{\circ} \mathrm{C}$ to $0.90^{\circ} \mathrm{C}$ ) for the right hand compared with the left at the thenar test site. The magnitude of the difference between left and right hand side was about twice as large for warmth as for cold (table 3). Measurements from the distal phalanges of the second digit showed less perceptual sensibility both to cold and warmth, resulting in neutral zone gaps double the width of the thenar measurements (figs 1 and 2).

OUTCOME RELATIVE TO EXPOSURE TO VIBRATION Reduced sensibility was found for warmth and cold thermal perception thresholds relative to the categories of exposure to vibration (figs 1, 2 , and 3). The contribution to the neutral zone gap was comparable with those from the perception of warmth and cold (figs 1 and 2).

Only for the digits on the left hand side was the contribution greater for cold. The difference between the three categories of exposure to vibration was significant for the neutral zone at the thenar test site both for the left $(p=0.014)$ and the right hand (0.001) side. The 


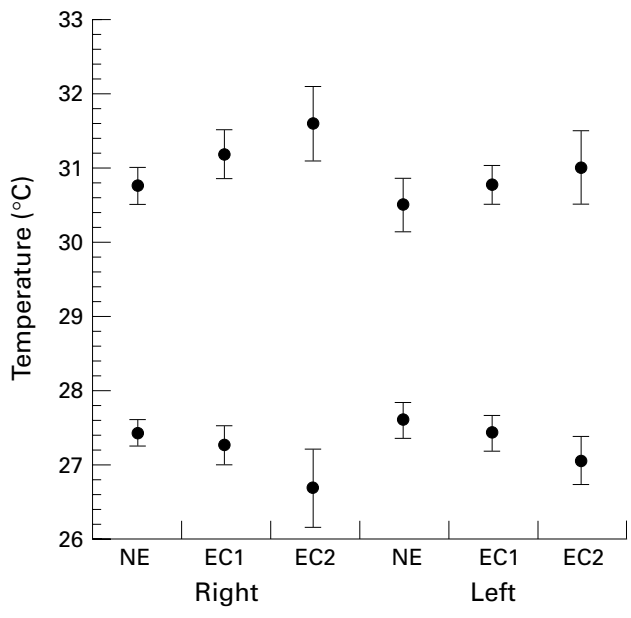

Figure 1 Mean (exposure to vibration) thermal perception thresholds measured at the thenar eminence for warmth (upper row) and cold (lower row) for the right and the left hand sides relative to exposure categories (NE $C V E=0 \mathrm{mh} / \mathrm{s}^{2}, E C 1 \mathrm{CVE} \leqslant 24000 \mathrm{mh} / \mathrm{s}^{2}, \mathrm{EC} 2 \mathrm{CVE}>24$ $\left.000 \mathrm{mh} / \mathrm{s}^{2}\right)$. The number of subjects in each exposure category is given in table 1.

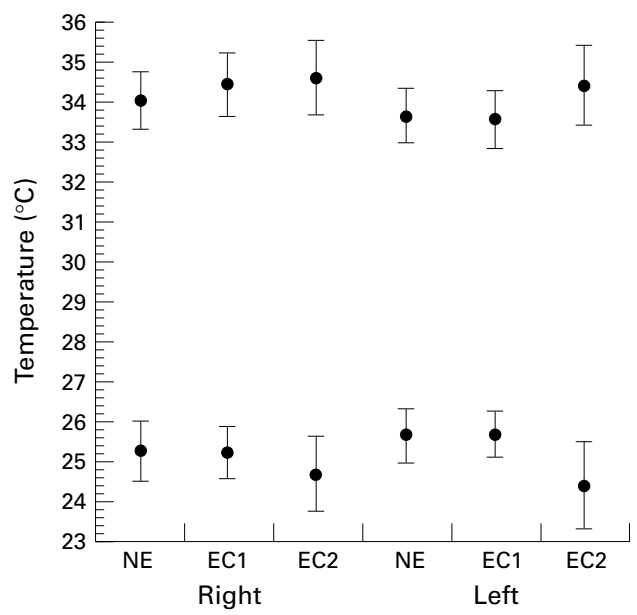

Figure 2 Mean (95\% CI) thermal perception thresholds measured on the second digit for, warmth (upper row) and cold (lower row) for the right and the left hand sides relative to exposure categories $\left(N E C V E=0 \mathrm{mh} / \mathrm{s}^{2}, E C 1\right.$ $\left.C V E \leqslant 24000 \mathrm{mh} / \mathrm{s}^{2}, E C 2 C V E>24000 \mathrm{mh} / \mathrm{s}^{2}\right)$. The

number of subjects in each exposure category is given in table 1.

difference for the underlying warmth and cold thresholds were all significant except for the perception of warmth on the left hand.

The risk of having contracted reduced thermal sensibility was increased for all test sites except for right hand digit 2 neutral zone measurements with cumulative lifetime exposure. The risk was higher for the thenar measurements than the finger measurements (table 4).

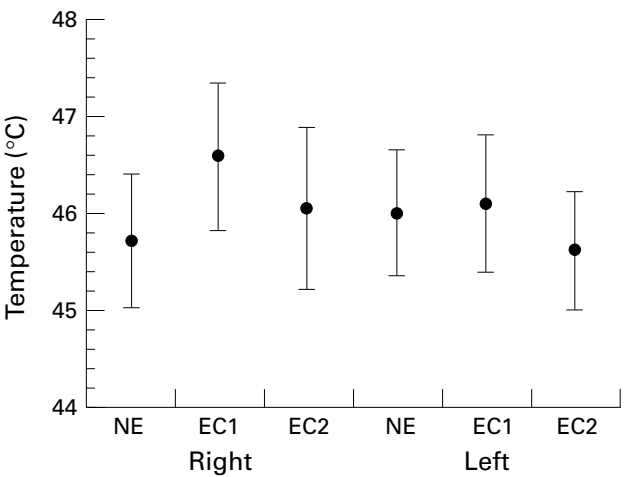

Figure 3 Mean (95\% CI) thermal perception thresholds measured at the thenar eminence for heat pain, for the right and the left hand sides relative to exposure categories (NE $C V E=0 \mathrm{mh} / \mathrm{s}^{2 ;} E C 1 \mathrm{CVE}=\leqslant 24000 \mathrm{mh} / \mathrm{s}^{2} ; E C 2 \mathrm{CVE}>24$ $000 \mathrm{mh} / \mathrm{s}^{2}$ ). The number of subjects in each exposure category is given in table 1.

When the contrast was based on the past 5 years of exposure comparable results with lifetime exposure were found (table 4).

In logistic regression modelling a $4000 \mathrm{mh} / \mathrm{s}^{2}$ change in cumulative exposure increases the risk of contracting a wider neutral zone by $18 \%$ (95\% CI 1.06 to 1.32 ) for the right hand side and $18 \%$ (95\% CI 1.05 to 1.32 ) for the left hand side, controlling for age and skin temperature. A linear regression model of exposure explains $7 \%$ of the variation in neutral zone gap (right hand). One unit change $\left(4000 \mathrm{mh} / \mathrm{s}^{2}\right)$ in exposure increases the neutral zone gap by $0.14^{\circ} \mathrm{C}$.

OUTCOME RELATIVE TO NOCTURNAL

PARAESTHESIA

Subjects with symptoms of nocturnal numbness have an increased risk of having wider neutral zones. The rate ratio for an increased neutral zone at the thenar eminence was 2.80 (95\% CI 1.17 to 6.67 ) for the right hand and 2.72 (95\% CI 1.12 to 6.63 ) for the left hand.

\section{Discussion}

Hand intensive work including exposure to vibration was, in this cross sectional study, associated with an increased risk of developing impaired thermal perception. This outcome was consistent with the results from clinical experience, ${ }^{14}$ threshold shift measurements, ${ }^{5}$ clinical case series, ${ }^{15-18}$ and case-control studies. ${ }^{19}$ Virokannas et $a l^{19}$ found reduced cold perception thresholds and wider neutral zones in lumberjacks compared with matched controls. This constituted a neutral zone pattern similar to that found for the crude values by

Table 4 Rate ratios (95\% CIs) for cumulative exposure versus non-exposure to vibration (lifetime and follow up period)

\begin{tabular}{|c|c|c|c|c|c|c|c|c|c|c|}
\hline \multirow[b]{2}{*}{ Test site } & \multirow[b]{2}{*}{ Hand side } & \multirow[b]{2}{*}{ Exposure period } & \multicolumn{2}{|c|}{ Warmth } & \multicolumn{2}{|l|}{ Cold } & \multicolumn{2}{|c|}{ Neutral zone } & \multicolumn{2}{|c|}{ Heat pain } \\
\hline & & & $R R$ & $95 \% C I$ & $R R$ & $95 \% C I$ & $R R$ & $95 \% C I$ & $R R$ & $95 \% C I$ \\
\hline \multirow[t]{4}{*}{ Digit 2} & Right & Lifetime exposure & 1.30 & 0.57 to 2.94 & 1.09 & 0.47 to 2.73 & 0.86 & 0.42 to 1.76 & - & - \\
\hline & Left & & 1.66 & 0.75 to 3.65 & 1.41 & 0.53 to 3.74 & 2.48 & 0.89 to 6.94 & - & - \\
\hline & Right & 1987-92 exposure & 1.20 & 0.55 to 2.62 & 1.86 & 0.79 to 4.36 & 1.08 & 0.50 to 2.31 & - & - \\
\hline & Left & & 2.24 & 0.79 to 4.36 & 1.86 & 0.79 to 4.36 & 3.55 & 1.69 to 7.49 & - & - \\
\hline \multirow[t]{4}{*}{ Thenar } & Right & Lifetime exposure & 2.32 & 0.93 to 5.80 & 4.03 & 0.96 to 16.99 & 4.28 & 1.02 to 17.96 & 1.46 & 1.19 to 1.79 \\
\hline & Left & & 2.14 & 1.18 to 4.25 & 2.35 & 0.70 to 7.88 & 2.20 & 0.65 to 7.44 & 1.59 & 0.54 to 4.69 \\
\hline & Right & 1987-92 exposure & 1.65 & 0.83 to 3.29 & 3.20 & 1.34 to 7.65 & 2.84 & 1.22 to 6.59 & 2.41 & 1.06 to 5.52 \\
\hline & Left & & 1.57 & 0.69 to 3.57 & 3.65 & 1.47 to 9.09 & 1.97 & 0.78 to 5.02 & 1.16 & 0.43 to 3.15 \\
\hline
\end{tabular}


Bovenzi et al. ${ }^{20}$ In that study the difference disappeared after adjustment for age and drinking habits. Supporting evidence for a possible relation between exposure to vibration and thin fibre neuropathy has also been gained from ultrastructural examinations of nerves from rats exposed to local vibration in experimental settings. This morphological study shows lesions particularly in the thin non-myelinated nerve fibres close to the vibration source. ${ }^{4}$ Morphological studies of peripheral nerves in humans exposed to vibration indicate that demyelination may be the primary lesion. ${ }^{21}$ Results from investigations of series of patients indicated that abnormal temperature thresholds were more common and seemed to have developed at an earlier stage than abnormal vibration thresholds. ${ }^{16}$

The assessment of the exposure to vibration in these epidemiological studies on hand-arm vibration and thermal perception was a cumulative mean operating time of 20100 hours for chain saw operators, ${ }^{19} 11$ years of forestry work,,$^{20}$ and 10.5 years of chain saw operating (one subgroup). ${ }^{22}$ In our study the mean frequency weighted energy equivalent acceleration during a whole lifetime was $2.9 \mathrm{~m} / \mathrm{s}^{2}$ for the right hand and $2.3 \mathrm{~m} / \mathrm{s}^{2}$ for the left hand. ${ }^{9}$ In our study, we found an exposure-response relation between cumulative vibration and impairment in thermal perception. Exposure to vibration lower than the recommended European Union threshold level showed signs of being a health hazard. To our knowledge only one additional study, that by Ekenvall et al, ${ }^{16}$ has focused on the exposure-response relation. In their study, temperature thresholds were not related to dose of exposure, by contrast with our findings. Investigators considering vibration and thermal perception have noticed a reduced sensibility in the right hand compared with the left ${ }^{15}{ }^{16}$ but no study so far has separated the exposure to vibration for each hand. The 0.80 exposure coefficient between the non-dominant (mainly left) and the dominant (mainly right) hand was possible to recognise in the results by the difference between the measurements in the right and left hand sides. Studies on subjects not exposed to vibration have found that perception thresholds values are normally symmetric for the left and right hands. ${ }^{11} 23$

Risk assessment based on exposure to vibration during the past 5 years preceding the investigation showed risk estimates comparable with lifetime exposure estimates.

The risk of developing impaired thermal sensibility increases by $18 \%$ for each year of work that entailed vibration, corresponding to an exposure at the recommended standard level, indicating that sensorineural effects can appear at lower levels of exposure than for white fingers.

Studies on subjects reporting symptoms of hand-arm vibration syndrome have reported reduced thermal perception. ${ }^{16}{ }^{18}{ }^{24}$ We found also an increased risk and wider neutral zones among subjects with nocturnal paraesthesia. This result might possibly be confounded as vibration is related both to symptoms and the effect on the sensory neural system.

Among the few studies dealing with the threshold of perception of heat pain and vibration, Ekenvall et $a l^{25}$ reported that heat pain sensitivity was reduced in a group $(n=10)$ of patients with hand-arm vibration syndrome compared with healthy controls. In a subsequent study of a group of dentists exposed to vibration $(n=44)$, the results indicated that injury to thin nerve fibres, as assessed by the heat pain threshold, is not a dominant finding. ${ }^{15}$ In their study the pain thresholds for heat contact were similar in both hands, in the second and fifth fingers as well as among the dentists with long and short term exposure to vibration. In our study we found no higher thresholds for perception of pain for the categories with the highest exposure to vibration.

As opposed to the outcome from animal experiments there is the clinical finding that compression lesions usually result in a relative sparing of sensation compared with motor function. These findings can probably be explained in terms of compression causing structural damage in large myelinated fibres rather than in small unmyelinated fibres. Large fibres being more susceptible to ishaemia as well as to compression. ${ }^{26}$

\section{STUDY DESIGN CONSIDERATIONS}

Possible misclassification with respect to disease The results of various studies that used different methods for measurements are hardly comparable. $^{27}{ }^{28}$ The forced choice method is more precise than the method of limits ${ }^{29}$ and the alternating difference of limits method introduces less sensitive measurements than the measurement of warmth and cold separately. ${ }^{29}$ In our study we used a standardised method of limits with separate assessment of warmth and cold individually measured from a thermally indifferent baseline. Touch and vibration are relatively easy to study in quantitative sensory tests. ${ }^{30}$ It is more complicated to investigate thermal perception because four different perceptions (cold pain, cold, warmth, and heat pain) are evoked along the stimulus continuum. The presumption that lesions to the neuron result in an increased sensory threshold may be misleading. For each channel there might be either hypoaesthesia, hyperaesthesia, hypoalgesia, or hyperalgesia irrespective of the result for the other perceptions. ${ }^{31}$ The overlapping between the four thermoreceptive neural channels introduces another difficulty in interpreting the data. Thus the lack of a clear effect on the threshold for heat pain among the workers in our study exposed to vibration cannot exclude a possible lesional somatosensory influence from the exposure, as the effect of this may also be a lowering of the threshold (apart from the $52^{\circ} \mathrm{C}$ upper limit). The multiple and unrelated perception of thermal sensations imply that it is not legitimate for us to draw conclusions about the status of all the small calibre afferents when testing a single perception only. 
Possible selection bias

A bias of possible health selection is an integral disadvantage of the cross sectional study design. In this study we also introduced an extra selection bias by excluding all subjects with signs of polyneuropathy or former hand surgery. The discrete symptoms from thin fibre neuropathy make this outcome factor a less probable cause of selection. Other arguments supporting a low selection bias in our study, stem from the need that the company have for a skilled workforce, which could counterbalance the selection of only healthy members from the source population, and the low $(<4 \%)$ yearly turn over in the population studied.

\section{Possible confounding}

Adaptation - that is, the diminution of perceived sensation with a constant stimulus-is thought to play a minimal part in the present study. The minor initial variability in threshold with repetitive stimulation is interpreted rather as a learning effect with a shift to a higher criterion instead of adaptation. We used the mean of all 10 and all five trials for calculating the thresholds for warmth, cold, and pain respectively. In our study the thresholds remained fairly stable during the trial and no trend over the consecutive trials was found. Thus, the thresholds obtained were regarded as valid.

No significant covariates of thermal thresholds are available in the scientific literature apart from the Vietnam experience study. ${ }^{32}$ In that study the main covariates of current interest for measurements of thermal perception of a finger were examiner bias, skin temperature, and smoking. ${ }^{33}$ These variables did not significantly contribute to the results in our logistic model, although skin temperature was retained in the final model because of its presumed biological importance. Influence from the examiner was controlled for in that all subjects were tested by the same technician and with the same apparatus.

Reduced finger temperature is found in some subjects with white fingers induced by vibration, ${ }^{34}$ which might be reflected by a difference between exposed and unexposed workers. Asymmetric effects on the median and ulnar nerve in workers exposed to vibration, despite the same hand temperature, have been put forward in opposition to this hypothesis. ${ }^{34}$ We did not find any temperature difference between exposed and unexposed subjects.

The method of limits used includes a reaction time component. ${ }^{35}$ The rate of increase of stimulus temperature introduces artefactual increases in threshold. The influence of the rate of increase in skin temperature is larger for the perception of warmth than for cold. In this study both cold and warmth contributed to the effect of vibration. The thermostimulation variables, including contact area $^{36}$ and rate of temperature increase, due to the preset contact area on the thenar test site, were less influential and were not regarded as the main validity issues as they were on the digital measurements where the contact area was not controlled for.

\section{Conclusions}

Conventional clinical and laboratory investigations of subjects with neurological sensory disorders fall short in evaluating the status of small calibre afferent systems. ${ }^{31}$ Referring to the aims of our cross sectional study of mechanics exposed to vibration and office workers, which focused specifically on these thin fibre afferents, the outcome showed an increased risk for disturbed thermal perception among the exposed workers, and a relation between cumulative exposure to vibration and thermal sensory function. The results of the study indicated sensory impairment, as assessed by increased perception thresholds for warmth and lowered thresholds for cold, whereas ambiguous results were found for the perception of heat pain. Subjects with symptoms of nocturnal paraesthesia stand to have an increased risk of wider neutral zones. The effect appeared at vibration levels currently suggested as being safe and below the guiding standard. Quantitative sensory testing of thermal perception offers a chance to assess this specific hazard to the peripheral sensorineural system associated with hand intensive work entailing vibration.

Financial support from the Swedish Work Environment Fund (Project No 91-1640) is gratefully acknowledged. We also express our thanks to Ms Inger Nyman for carrying out the thermal sensory testing.

1 Bruce B, ed. Musculoskeletal disorders and workplace factors. A critical review of epidemiologic evidence for work-related musculoskeletal disorders of the neck, upper extremity and low back, 2nd ed. Cincinnati: DHHS (NIOSH), 1997:41.

2 Hagberg M, Silverstein B, Wells R, et al. Work related musculoskeletal disorders. A reference book for prevention. London: Taylor and Francis, 1995.

3 Lindblom U, Ochoa J. Somatosensory function and dysfunction. In: Asbury A, McKhann G, McDonald I, eds. Diseases of the nervous system. Clinical neurobiology, 2 ed. London: WB Saunders, 1992;1:213-28.

4 Lundborg G, Dahlin LB, Hansson H-A, et al. Vibration exposure and peripheral nerve fiber damage. 7 Hand Surg 1990;15A:346-51.

5 Hirosawa I, Nishiyama K, Watanabe S. Temporary threshold shift of temperature sensation caused by vibration exposure. Int Arch Occup Environ Health 1992;63:531-5.

6 Hirosawa I, Wantanabe S, Fukuchi Y, et al. Availability of temperature sense indices for diagnosis of vibration temperature sense indices for diagnosis of vibratio
disease. Int Arch Occup Environ Health 1983;52:215-22.

7 Fruhstorfer H, Lindblom U, Schmidt WG. Method for quantitative estimation of thermal thresholds in patients. $\mathcal{F}$ Neurol Neurosurg Psychiatry 1976;39:1071-5.

8 International Standards Organisation. Mechanical vibration: guidelines for the measurement and the assessment of human exposure to hand-transmitted vibration. Geneva: ISO, 1986. (ISO 5349.)

9 Burström L, Lundström R, Hagberg M, et al. Comparison of different measures for hand-arm vibration exposure. Safety Science 1998;28:3-14.

10 International Standards Organisation. Vibration and shock: guidelines for the measurement and the assessment of human exposure to hand-transmitted vibration. Geneva: ISO, 1986. (ISO 5349.)

11 Meh D, Denislic M. Quantitative assessment of thermal and pain sensitivity. F Neurol Sci 1994;127:164-9.

12 Gerr F, Letz R. Covariates of human peripheral nerve function: vibrotactile and thermal thresholds. Neurotoxicol Teratol 1994;16:105-12.

13 Amended proposal for a Council Directive on the minimum health and safety requriements regarding the exposure of workers to the risks arising from physical agents: individual directive in relation to article 16 of Directive 89/391/EEC. Brussels: Official fournal of the European Communities 1994; 230:16-22.

14 Taylor W, Ogston SA, Brammer AJ. A clinical assessment of 78 cases of hand-arm vibration syndrome. Scand 7 Work Environ Health 1986;12:265-8.

15 Ekenvall L, Nilsson BY, Falconer C. Sensory perception in the hands of dentists. Scand $f$ Work Environ Health 1990;16:334-9.

16 Ekenvall L, Gemne G, Tegner R. Correspondence between neurological symptoms and outcome of quantitative
sensory testing in the hand-arm vibration syndrome. $B r \mathcal{F}$ lnd Med 1989;46:570-4. 
17 Ekenvall L, Nilsson BY, Gustavsson P. Temperature and vibration thresholds in vibration syndrome. Br f lnd $\mathrm{Med}$ vibration thresh

18 Strömberg T, Dahlin LB, Brun A, et al. Structural nerve changes at wrist level in workers exposed to vibration. Occup Environ Med 1997;54:307-11.

19 Virokannas H, Virokannas A. Temperature and vibration perception thresholds in workers exposed to hand-arm vibration. Cent Eur F Public Health 1995;3:66-9.

20 Bovenzi M, Zadini A, Franzinelli A, et al. Sensorineural disorders in forestry workers using chain saws. In: Dupuis $\mathrm{H}$, Christ E, Sandover DJ, et al, eds. 6th International Conference on Hand-Arm Vibration. Bonn: Schriftenreihe des Hauptverbandes der gewerblichen Berufsgenossenschaften, 1992:279-84.

21 Strömberg T, Dahlin LB, Rosen I, et al. Neurophysiological findings in vibration-exposed male workers [doctoral thesis] Malmö: Lund University, 1997.

22 Hirosawa I. Original construction of thermo-esthesiometer and its application to vibration disease. Int Arch Occup and its application to vibration

23 Long AD. Hand differences and reported intensity of nocicLong AD. Hand differences and reported intensity

24 Okada A, Nakamura H. Some features of peripheral circulatory and nervous function in workers with hand-held vibratory tools. In: Dupuis H, Christ E, Sandover DJ, et al, eds. 6th International Conference on Hand-Arm Vibration. Bonn: Schriftenreihe des Hauptverbandes der gewerblichen Berufsgenossenschaften, 1992:37-60.

25 Ekenvall L, Lindblad LE, Carlsson A, et al. Afferent and efferent nerve injury in vibration white fingers. F Auton Nerv Syst 1988;24:261-6.
26 Lundborg G. Nerve injury and repair. New York: Churchill Livingstone, 1988

27 Swerup C, Nilsson B. Dependence of thermal thresholds in man on the rate of temperature change. Acta Physiol Scand 1987;131:623-4

28 Yarnitsky D, Sprecher E. Thermal testing: normative data and repeatability for various test algorithms. F Neurol Sci 1994;125:39-45.

29 Hilz MJ, Glorius S, Beric A. Thermal perception thresholds: influence of detennination paradigm and reference temperature f Neurol Sci 1995;129:135-40.

30 Boivie J, Hansson P, Lindblom U, eds. Touch, temperature, and pain in health and disease: mechanisms and assess-
ments. In: Progress in pain research and management. VoI 3. ments. In: Progress in pain
Seattle: IASP press, 1994.

31 Verdugo R, Ochoa JL. Quantitative somatosensory thermotest. A key method for functional evaluation of small calibre afferent channels. Brain 1992;115:893-913.

32 Gerr F, Letz R. Vibrotactile threshold testing in occupational health: a review of current issues and limitations. Environ Res 1993;60:145-59.

33 Gerr F, Letz R. Covariates of human peripheral nerve function: III. Effects of reported drinking. Neurotoxicol Teratol 1994;16:113-22.

34 Brismar T, Ekenvall L. Nerve conduction in the hands of vibration exposed workers. Electroencephalogr Clin 1992;85: 173-6.

35 Yarnitsky D, Ochoa I. Warm and cold specific somatosensory systems. Brain 1991;114:1819-26.

36 Autrum H, lung R, Loewenstein WR, et al, eds. Handbook of sensory physiology. Volll. Berlin: Springer Verlag, 1973.

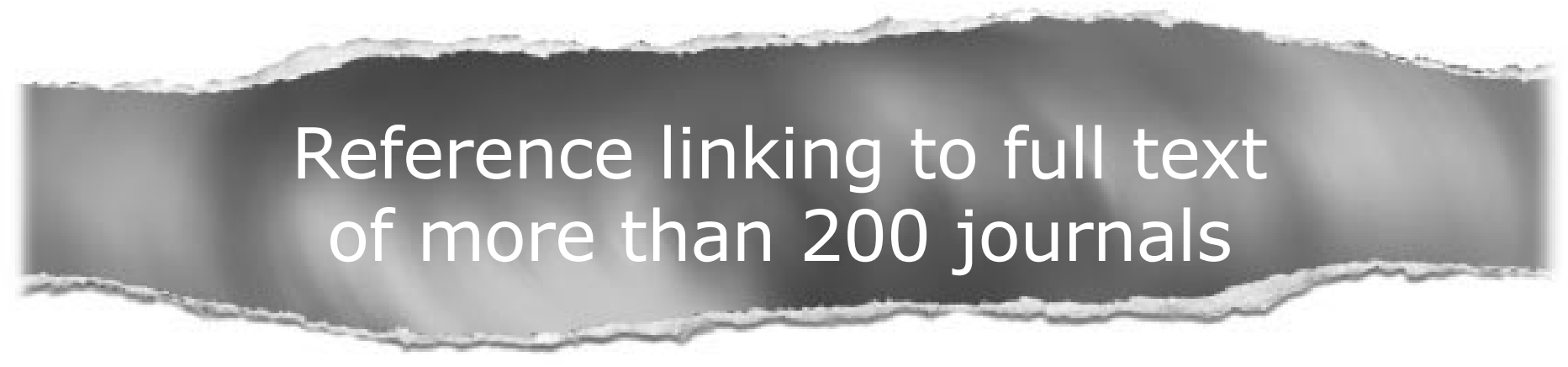

Toll free links

You can access the FULL TEXT of articles cited in Occupational and Environmental Medicine online if the citation is to one of the more than 200 journals hosted by HighWire (http://highwire.stanford.edu) without a subscription to that journal.

There are also direct links from references to the Medline abstract for other titles.

www.occenvmed.com 